\title{
The Possible Observation of Slow Slip Events Prior to the Occurrence of the 1999 Chi-Chi Earthquake
}

\author{
Cheng-Horng Lin* \\ Institute of Earth Sciences, Academia Sinica, Taipei, Taiwan \\ Received 12 April 2011, accepted 23 September 2011
}

\begin{abstract}
Possible short-term precursors several days before the Taiwan Chi-Chi earthquake $\left(M_{w}=7.6\right)$ on 20 September 1999 were observed by examining crustal deformation that were directly integrated from broadband velocity seismograms. Significant deviations of the vertical displacement from a normal Earth tidal pattern on 15 - 19 September show some tiny surface crustal deformation having taken place several days in advance of the earthquake on 20 September. A series of slow slip events on the nearly horizontal plane (or decollement) at depths between 10 and $12 \mathrm{~km}$ provide a possible explanation for generating the anomalous crustal deformations before the earthquake. Although those slow slip events are not well constrained owing to limited observations at only two broadband seismic stations, their possibility is acceptable from a geological standpoint if the decollement beneath central Taiwan can be evidenced from both geological and geodetic studies. However, no matter what the exact mechanism was which generated the irregular earth tidal deformation several days before the 1999 Taiwan Chi-Chi earthquake, these anomalous crustal deformations might be considered to be possible short-term earthquake precursors.
\end{abstract}

Key words: Slow slip, Earthquake precursor, Chi-Chi earthquake, Tidal deformation

Citation: Lin, C. H., 2012: The possible observation of slow slip events prior to the occurrence of the 1999 Chi-Chi earthquake. Terr. Atmos. Ocean. Sci., 23, 145-159, doi: 10.3319/TAO.2011.09.23.01(T)

\section{INTRODUCTION}

Monitoring of crustal deformation has for many years been considered one of the most promising methods for detecting earthquake precursors. According to the elastic rebound theory (Reid 1910), crustal deformation for stored elastic energy is expected on either side of the fault before a large earthquake occurs. During the past century, scientists carefully searched for possible earthquake precursors utilizing a variety of crustal deformation observations including traditional levelling surveys, water wells, and strain meters (Sato 1977, 1982; Sagiya 1998; Linde et al. 1996). Although possible earthquake precursors have been claimed from anomalous crustal deformation (Castle et al. 1975; Sato 1977, 1982; Roeloffs 2006), a lack of reliable methods and consistent observations has left most scientists unconvinced. The difficulty in detecting demonstrable earthquake precursors from anomalously crustal deformation can be largely attributed to either: (1) observations not being appropriately

\footnotetext{
* Corresponding author

E-mail:lin@earth.sinica.edu.tw
}

obtained from nearby large earthquakes or (2) a resolution not being good enough to detect small crustal deformation before earthquakes. Therefore, the ability to achieve a highresolution of crustal deformation at appropriate locations, such as nearby large earthquakes, is likely to play an important role in earthquake prediction in the future.

In detecting possible earthquake precursors from small crustal deformation, careful examination of the irregularity of Earth's tidal pulses (crustal deformations caused by the tidal force) at the sea surface is both an important and popular method (Linde et al. 1988; Roeloffs 2006; Liu et al. 2009). It is well known that the Earth's tidal pulses are largely controlled by a combination of gravitational forces attributable to the moon and the sun. Without giving consideration to additional tectonic or other forces, a smooth harmonic form (sinusoidal pattern) composed of two high tides and two low tides can often be found on each day. On the other hand, irregular Earth tidal pulses are an indication of some additional force having been added into the crust disturbing the normal sinusoidal pattern. Since daily variations of solid-earth tidal stress are very small ( $\sim .05$ bar; Cochran 
et al. 2004), any slight additional force added into the crust will cause significant change causing deviation from the general pattern of Earth's tidal pulses. As a result, elaborate examination of the Earth's tidal pulses should show that this relationship is very sensitive to detecting small anomalous crustal deformations caused by any additional force in the crust.

In addition to traditional observations such as strainmeters and water wells, broadband seismic stations might provide another opportunity to observe possible earthquake precursors from Earth's tidal deformation (i.e., Houlié and Montagner 2007). Although Earth's tidal deformation can be accurately obtained from traditional strain-meters and water wells, worldwide the total number of these observation sites is very limited because they are often equipped with expensive instruments and require a high-cost of construction. Thus, opportunities for detecting crustal deformation nearby unpredictable large earthquakes are very low. On the other hand, a large number of observation sites for monitoring Earth's tidal deformation can be obtained from the ever increasing number of broadband seismic stations, even though they were not deployed for such a purpose. For observation of all earthquakes at different distances, broadband seismometers (such as STS-2 or CMG-3T) are designed for recording all seismic signals over a broad range of frequencies from hundreds of $\mathrm{Hz}$ to several micro $\mathrm{Hz}$. Thus, Earth tidal deformation can be observed from longperiod ground displacements that are directly integrated from broadband velocity seismograms without any complicated data process.

In this study, high-resolution crustal deformations are carefully extracted from the broadband seismic data in Taiwan before the 1999 Taiwan Chi-Chi earthquake $\left(M_{w}=7.6\right)$. To detect anomalous crustal deformation before the earthquake, the general patterns of the Earth's tidal pulses observed on any given day are compared to the days preceding and after the event to establish the general tidal pulse pattern. Theoretically tidal forces at the broadband seismic stations are further calculated using analytic solutions to confirm any anomalous crustal deformation. On regular days, as expected, vertical displacements that were directly integrated from the velocity seismograms recorded at all broadband seismic stations were clearly associated with tidal forces. However, some irregular Earth tidal pulses were obtained at two broadband seismic stations nearby the epicenter of the mainshock several days before the 1999 Taiwan Chi-Chi earthquake. These anomalous crustal deformations might be interpreted as a sequence of small slow slip events nearby the epicenter, and thus is worth consideration as a possible earthquake precursor of the 1999 Chi-Chi earthquake.

\section{THE 1999 TAIWAN EARTHQUAKE}

In 1999 , the Chi-Chi earthquake $\left(M_{w}=7.6\right)$ struck central Taiwan and killed more than 2400 residents (Shin et al. 2000). It was the most destructive earthquake in Taiwan since the 1935 Hsinchu-Taichung earthquake ( $M=$ 7.1), which killed at least 3500 people (Hsu 1971). Since the focal depth of the Chi-Chi earthquake was very shallow $(\sim 8.0 \mathrm{~km})$, it produced more than $80 \mathrm{~km}$ of significant surface ruptures along the Chelungpu fault, which is a typical thrust fault dipping 30 degrees to the east (Chang 2000; Chen et al. 2001; Lin 2007) (Fig. 1). In addition to generating more than twenty thousands aftershocks on the island of Taiwan (Lin and Ando 2004), significant post-seismic crustal deformation was broadly observed by a GPS survey throughout central Taiwan in the following 15 months (Yu et al. 2003). Both co- and post-seismic deformations generated by the large slips on the Chelungpu fault $(3-10 \mathrm{~m})$ as well as the nearly horizontal plane (i.e., a decollement, Suppe 1981) at depths around $10 \mathrm{~km}$ beneath the hangingwall show typical elastic behaviour in the upper crust ( $\mathrm{Yu}$ et al. 2001; Hsu et al. 2003). In general, surface rupture and crustal deformation during the earthquake as well as crustal relaxation after the earthquake agree well with the elastic rebound theory (Reid 1910). These observations strongly suggest that significant energy had accumulated in the elastic crust before the 1999 Taiwan Chi-Chi earthquake.

\section{ANOMALOUS CRUSTAL DEFORMATION}

To examine possible earthquake precursors to the 1999 Chi-Chi earthquake, crustal deformation has been extracted from continuous seismograms recorded at broadband seismic stations nearby the epicenter. The vertical displacements on the surface can be directly obtained by first removing the mean value and then integrating from the vertical velocity seismogram. Although the daily variations of the tidal forces are small (Cochran et al. 2004), vertical displacements show sinusoidal crustal deformation caused by the tidal force. For example, the daily plots of vertical displacements recorded at Station SSLB, a BATS station (Broadband Array in Taiwan for Seismology), nearby the epicentre of the 1999 Chi-Chi earthquake (Fig. 1), show the typical Earth-tidal-pulse pattern to consist of two high and low tides on every day in July, two months before the ChiChi earthquake (Fig. 2). The general patterns of tidal pulses on close days are extremely similar to each other, except on 29 and 30 July when the raw data were cut off by power, and 9 and 19 July in which some short-period perturbations were caused by large teleseismic events. This examination clearly shows that the crustal deformation recorded at the broadband seismic station for the entire month completely reflects the earth tidal effect without any significant disturbance by external forces. Similar patterns of crustal deformation caused by tidal force have been demonstrated at the vertical displacements at Station SSLB from January 1998 to June 1999 (18 months) (Fig. 3). Most of daily crustal de- 
formation shows a sinusoidal pattern, except for a few days when some seismic data were missing or disturbed by transmission problems such as several days in September 1998. In general, these results indicate that the crustal deformation caused by the tidal force can be well detected by broadband seismic stations.

Further examination of broadband seismic data from the BATS stations shows detectable anomalous crustal deformations nearby the epicenter area several days before the 1999 Chi-Chi earthquake. Vertical displacements integrated directly from broadband seismograms recorded at Stations SSLB and NACB indicate some irregular patterns in Earth's tidal deformation several days ahead of the earthquake on 20 September 1999 (Figs. 4a and b). The primary anomaly in crustal deformation on each day can be directly obtained by comparing its pattern within a few days before and after it. More detailed anomalies are estimated from the differences between the crustal deformation extracted from the broadband seismic data and caused by tidal forces, calculated using the theoretical tidal computation (MT80M) obtained from International Center for Earth Tides (ICET).

At the SSLB station, which is only $\sim 10 \mathrm{~km}$ away from the epicenter on the hanging wall of the Chelungpu fault
(Fig. 1), some anomalous crustal deformation was observed a few days preceding the mainshock. A regular harmonic form with two clear peaks and troughs was obtained on 12 - 14 September (Fig. 4a). These were basically similar to the regular sinusoidal pattern in July (Fig. 2). This regular pattern, however, changed on 15 - 20 September. At first, the pattern of that the tidal pulse lost the second trough expected on the regular days indicates a significant uplifting $(\sim 0.48 \mathrm{~mm})$ might occur in the latter half of the day on 15 September and thus. Further, some temporary subsidence that persisted for several hours was observed on the following days (16 - 20 September), just 4 days before the Chi-Chi earthquake. The maximum subsidence on each day ranged from 0.22 to $0.40 \mathrm{~mm}$, which is almost comparable to the level (order) of the daily deviation of the tidal deformation in general (Fig. 2). For example, the first peak expected on the daily pattern was unambiguously missing on 18 and 19 September. On 20 September, another subsidence $(\sim 0.22 \mathrm{~mm})$ was observed several hours before the earthquake. Furthermore, it is worth noting that the curve of vertical displacements on those two days had some higher frequency signals than those on the other days. In other words, some crustal deformation with higher frequency signals that

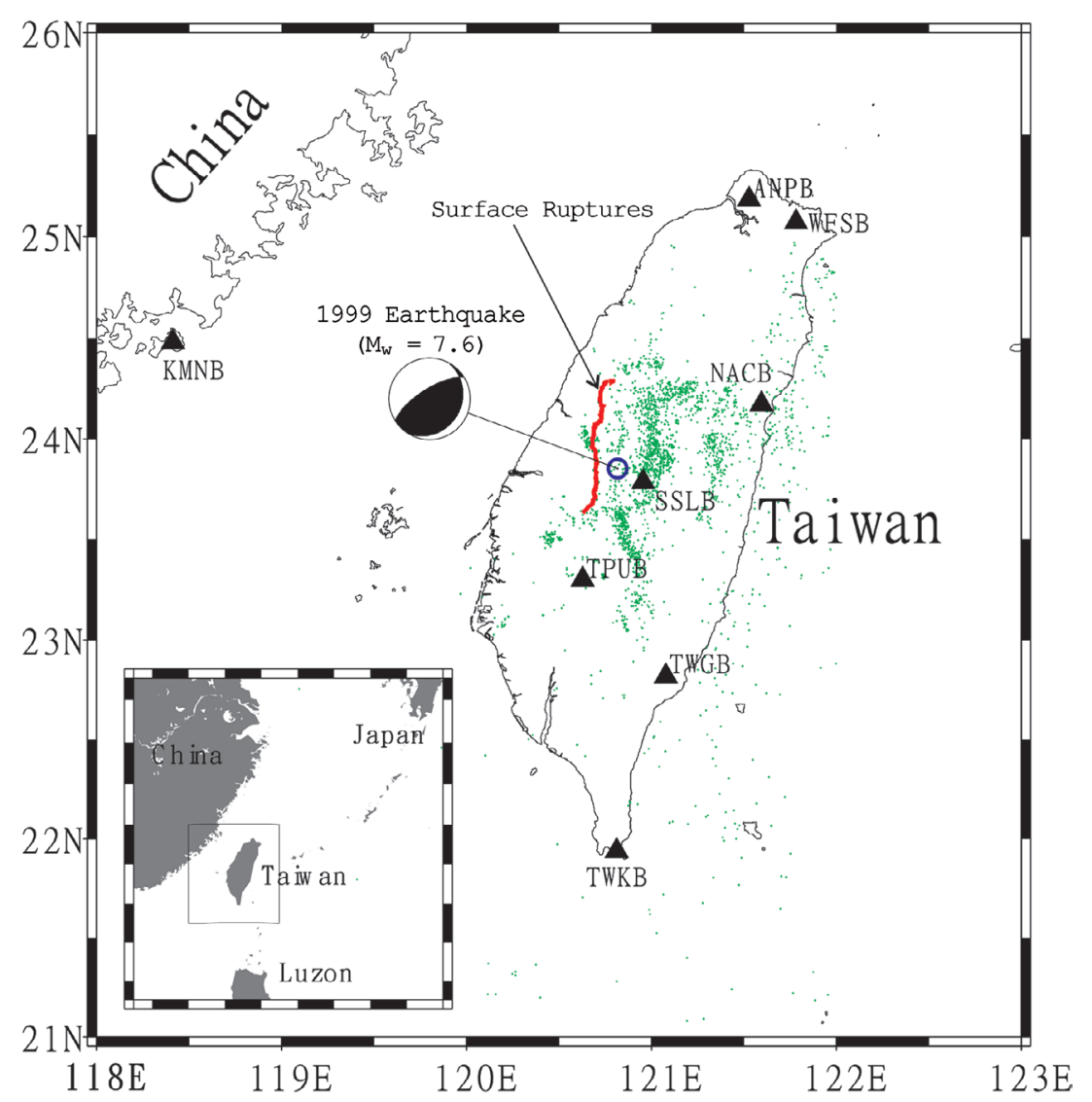

Fig. 1. Locations of the 1999 Taiwan Chi-Chi earthquake (circle), surface ruptures (thick line), larger aftershocks ( $\mathrm{M}_{\mathrm{L}}>3.5$ ) (small dots) and broadband seismic stations (triangles) in the Taiwan area. The focal mechanism of the main shock is also shown. The insert map shows the location of Taiwan in East Asia. 
could not be caused by the tidal forces was found on those days.

Like the anomalous crustal deformation observed at Station SSLB, some irregular patterns in the Earth's tidal pulses were also found at vertical displacements recorded at Station NACB from 16 to 20 September (Fig. 4b). On 16 and 17 September, at first, there was some slight uplifting $(0.29$ $-0.08 \mathrm{~mm})$ in the early hours followed by subsidence $(0.14$ $-0.16 \mathrm{~mm}$ ) in the mid and latter parts of the day (Fig. $4 \mathrm{~b}$ ). On 18 and 19 September, some subsidence was found at Station NACB in the latter hours while some subsidence was found at station SSLB in the early hours. In particular, on 18 September, a significant irregular pattern with a maximum subsidence of $0.56 \mathrm{~mm}$ was observed in the latter hours when the $2^{\text {nd }}$ calculated peak was totally missing at Station SSLB. On the other hand, a large subsidence $(0.32 \mathrm{~mm})$ was observed in the early hours when the $1^{\text {st }}$ peak was ab- sent at Station NACB. Again, the curve of vertical displacements on 17 - 19 September had some higher frequency signals. Those characteristics imply some other mechanisms or forces had been involved to produce unusual crustal deformation at Stations SSLB and NACB as well as highfrequency crustal deformation several days before the ChiChi earthquake because there was no significant change of weather conditions (such as typhoons) or any report of instrumentation problems in September 1999.

Except for stations SSLB and NACB, which are two of the available broadband seismic stations (BATS) at the hanging wall of the Chelungpu fault in 1999, there was no other anomalous crustal deformation observed at other broadband seismic stations several days before the 1999 Taiwan Chi-Chi earthquake. For example, vertical displacements at Station TWKB (Fig. 4c), located at the southern tip of Taiwan (Fig. 1), basically followed well the regular
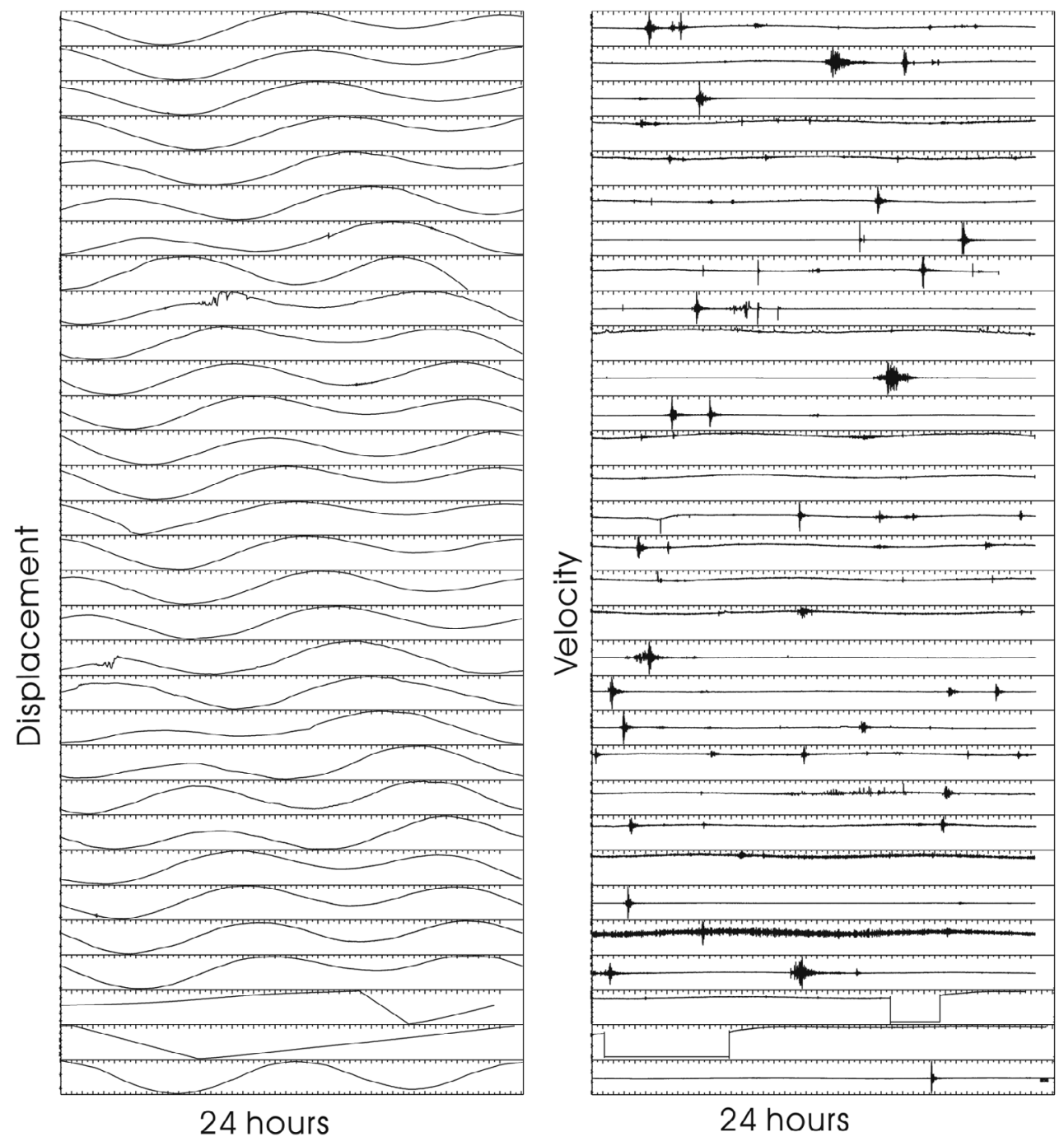

Fig. 2. Daily vertical displacement (left panel) and velocity (right panel) seismograms recorded at the broadband seismic station (SSLB) nearby the epicenter of the Taiwan earthquake in July 1999. Continuous seismograms recorded at 24 hours on every day from July 1 to 31 are shown by traces from top to down. 
(a)
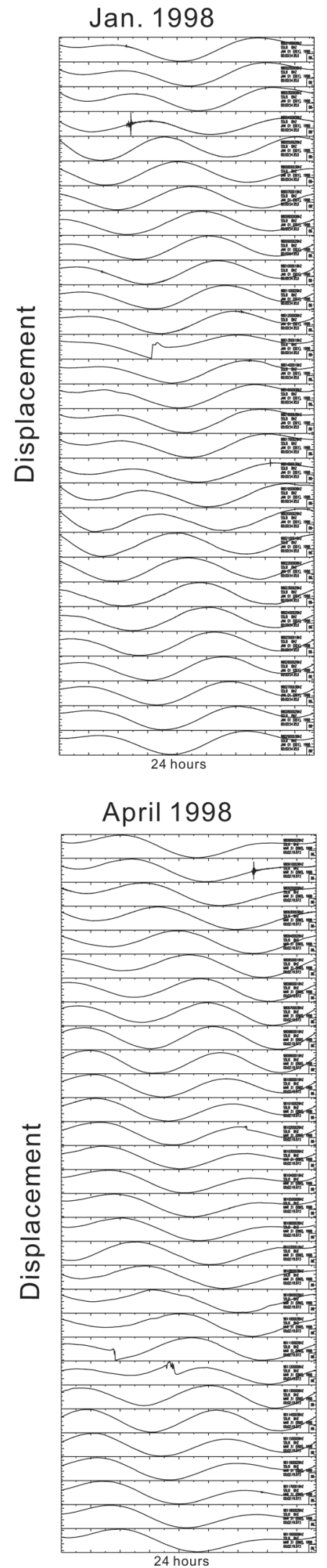

Feb. 1998

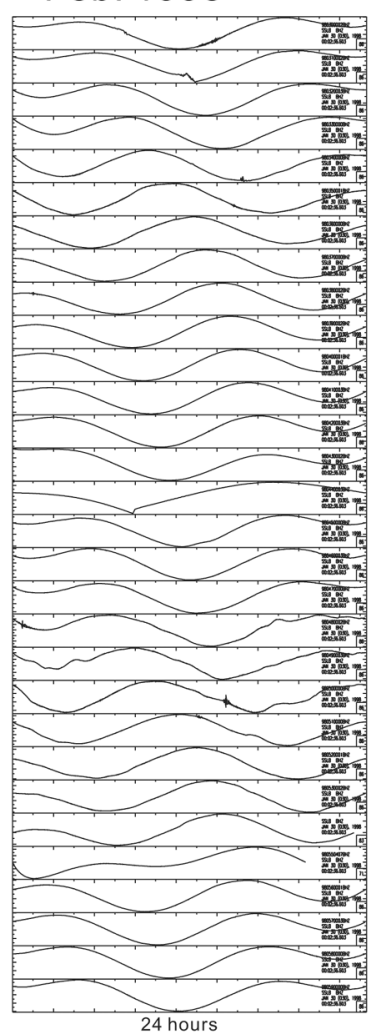

May 1998

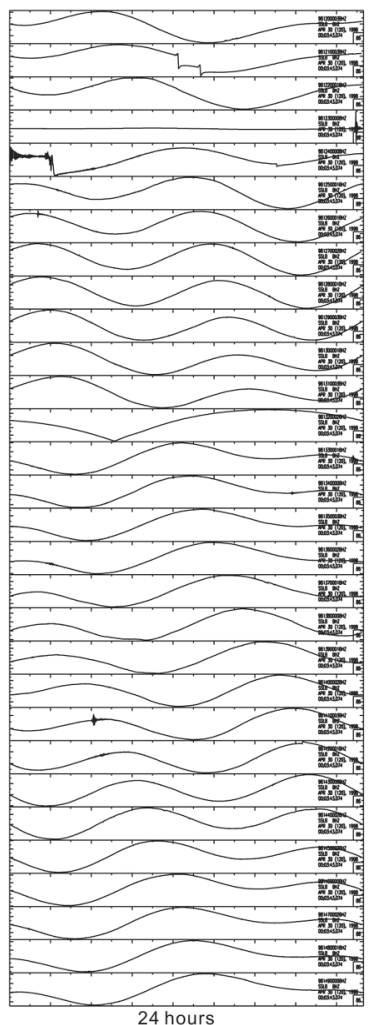

Mar. 1998

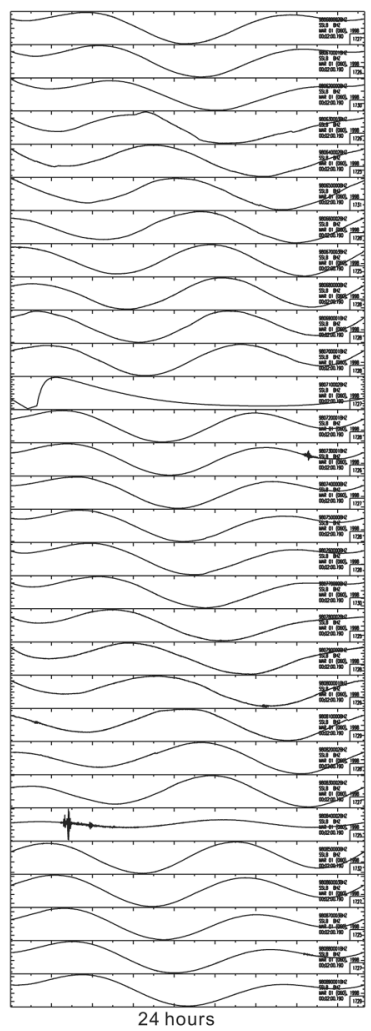

June 1998

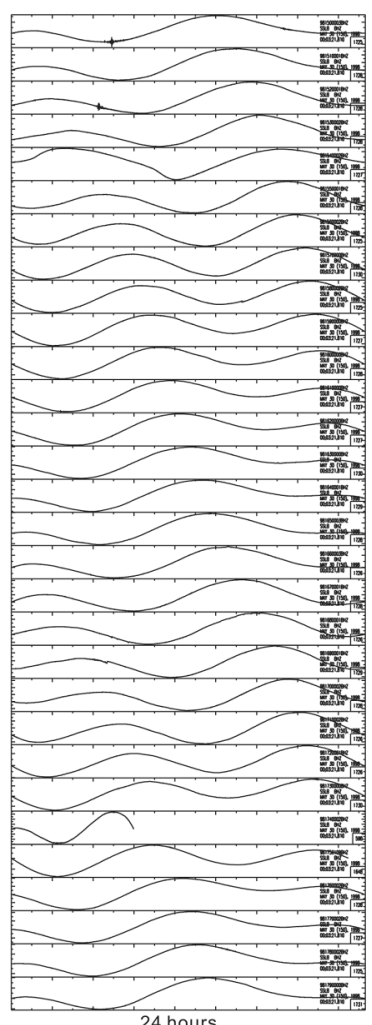

Fig. 3. Daily vertical displacements recorded at Station SSLB between (a) January and June, 1998 (b) July and December, 1998 as well as (c) January and June, 1999. 
(b)

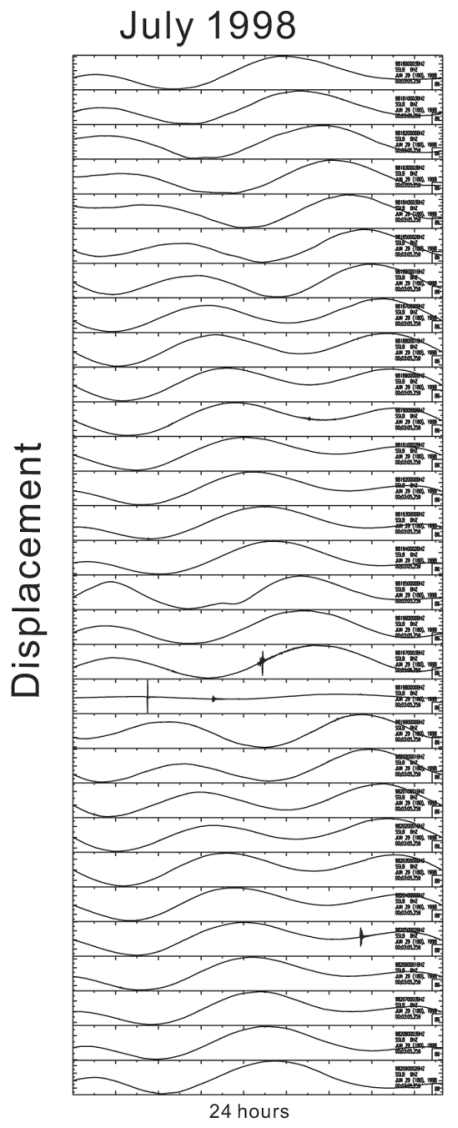

Oct. 1998

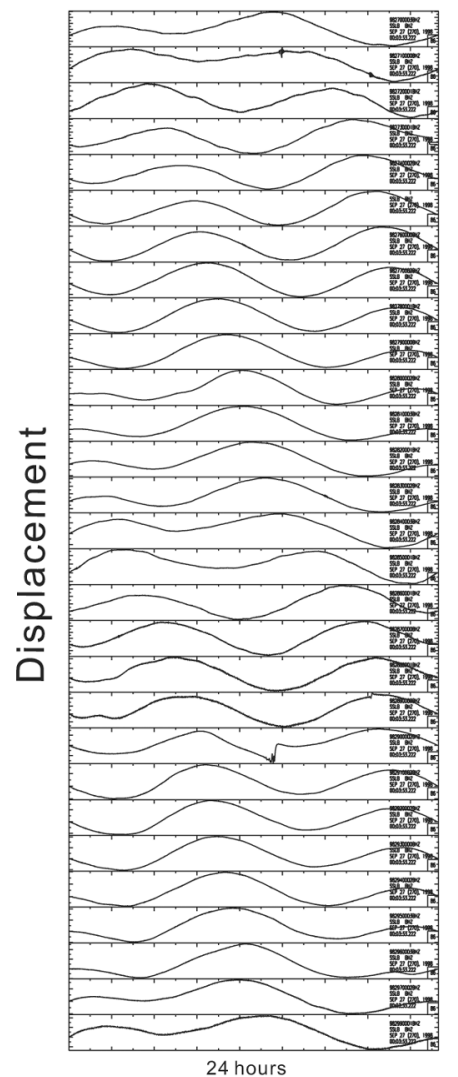

Aug. 1998

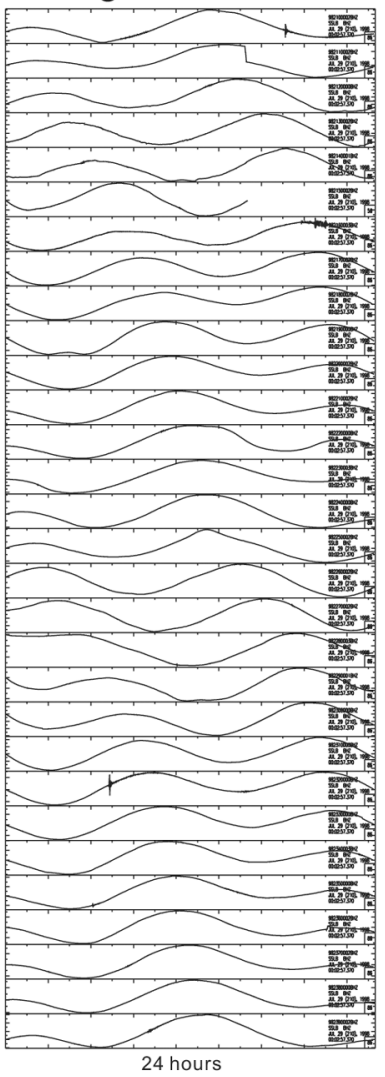

Nov. 1998

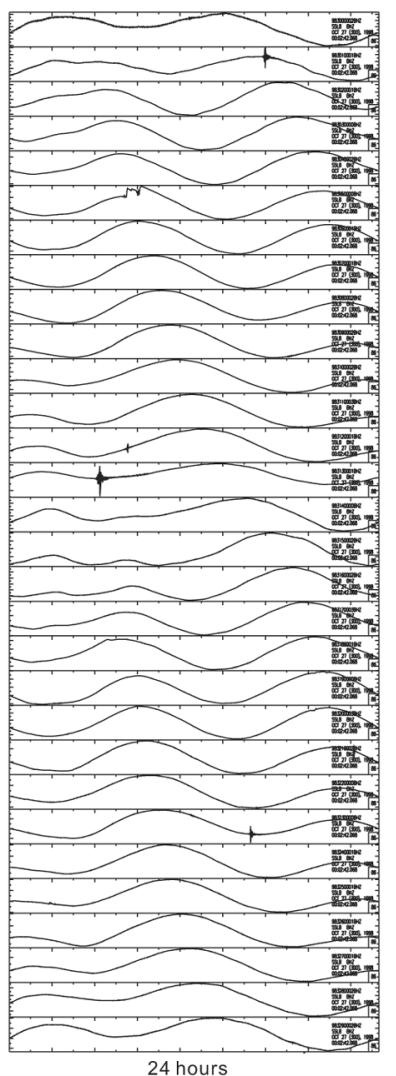

Fig. 3. (Continued)
Sept. 1998

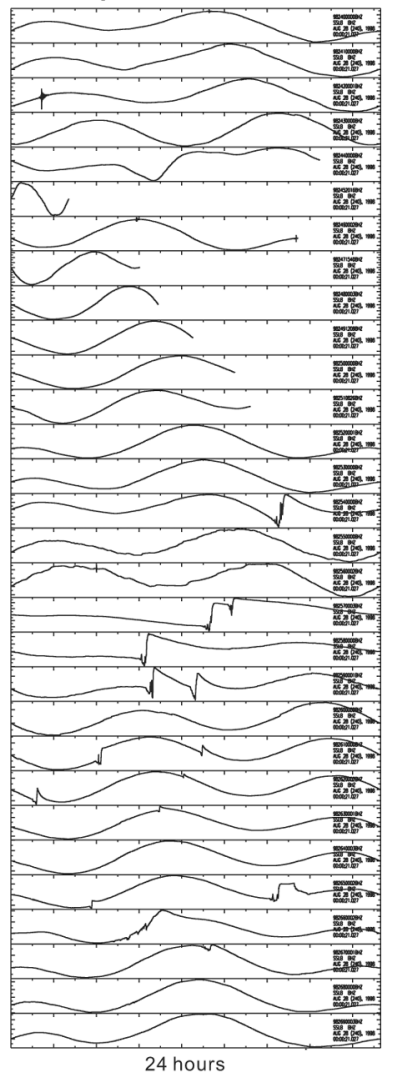

Dec. 1998

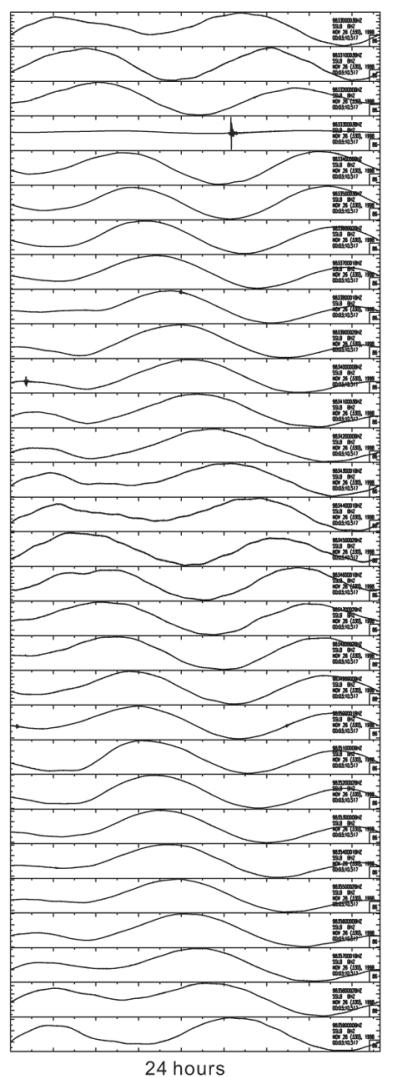


(c)

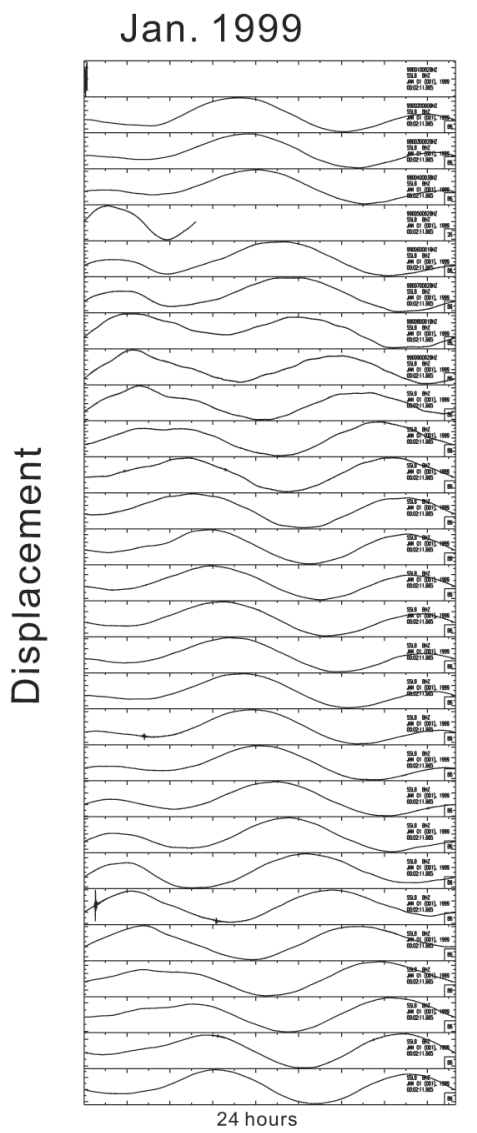

April 1999

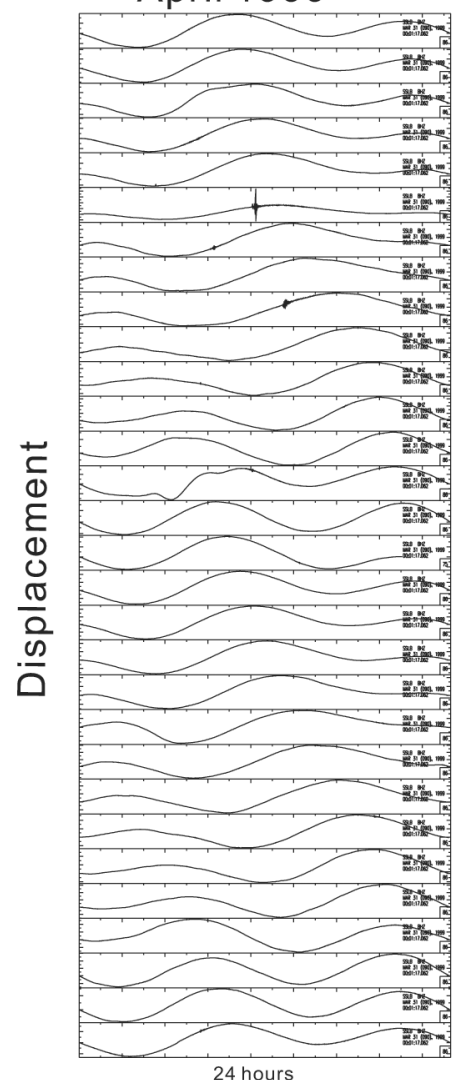

Feb. 1999

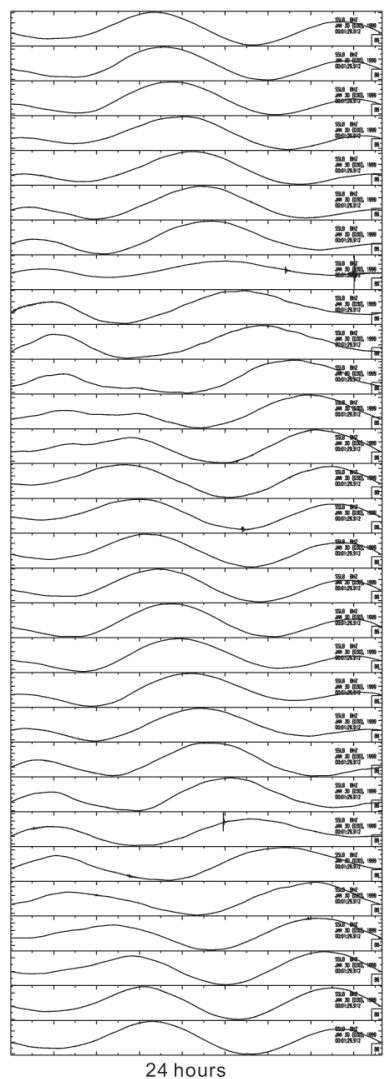

May 1999

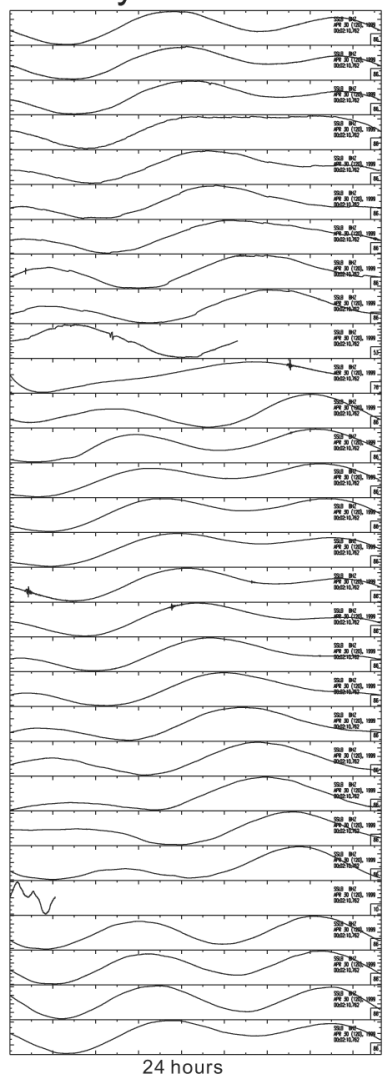

Fig. 3. (Continued)
Mar. 1999

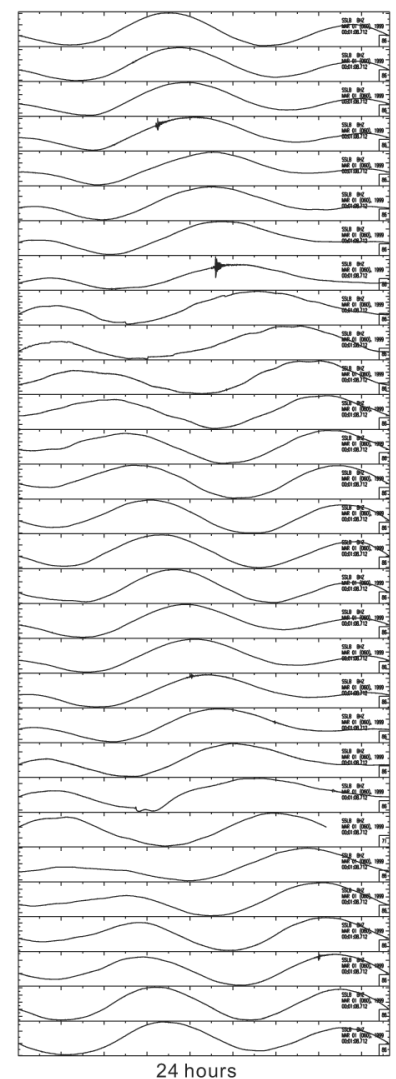

June 1999

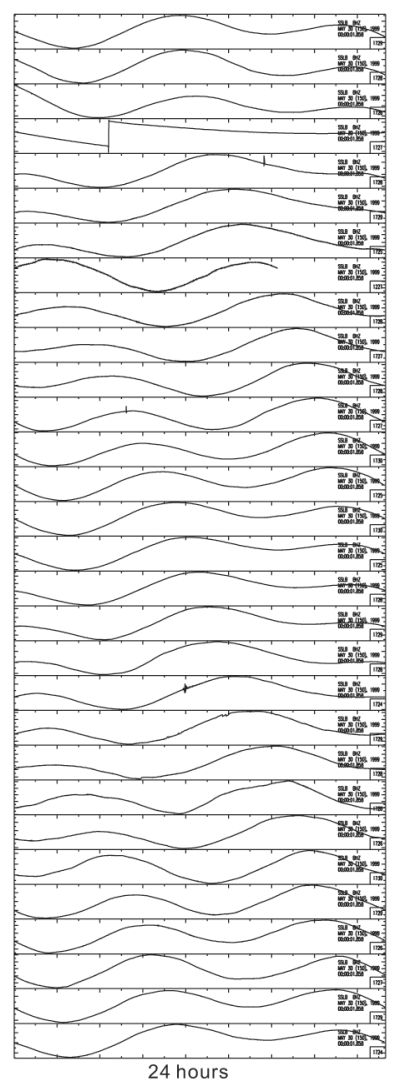


pattern of Earth's tidal force on every day, except on 13 September, which was disturbed by a teleseismic event.

\section{SLOW SLIP EVENTS}

One likely explanation for anomalous crustal deformations being observed only in central Taiwan several days before the Chi-Chi earthquake might be the occurrence of a series of small slow slip events (Heki et al. 1997; Hirose et al. 1999; Dragert et al. 2001). Irregular crustal deformation observed at broadband seismic stations on the surface indicates some elastic deformation occurred within the strained crust in addition to that evidenced by the expected response of tidal forces. Although tectonic earthquakes are often considered the most likely mechanism for generating anomalous crustal deformations, there was no earthquake detected in and around the epicenter several days before the ChiChi earthquake based on the CWB earthquake catalogue.
Alternatively, slow slip events perhaps played a role here because they can also generate crustal deformation but are not recorded by regular seismic stations due to their long rupture times (or slow slip). Also any anomalous crustal deformation persisting several hours can be explained simply by slow slip events.

For the Chi-Chi earthquake, to further quantitatively estimate the possibility of anomalous crustal deformation being generated by slow slip events, surface crustal deformation caused by simple faults has been calculated using Micap- $G$ software based on Okada $(1985,1992)$. Since the major post-seismic deformation or slip was detected on the decollement (i.e., a nearly horizontal gliding plane between two rock masses, Suppe 1981) using a GPS survey (Hsu et al. 2003), the slow slip events have been assumed to have occurred along nearly horizontal faults at depths of between 10 and $12 \mathrm{~km}$ beneath the hanging wall of the Chelungpu fault. At first, consideration is given to a significant uplift of (a)
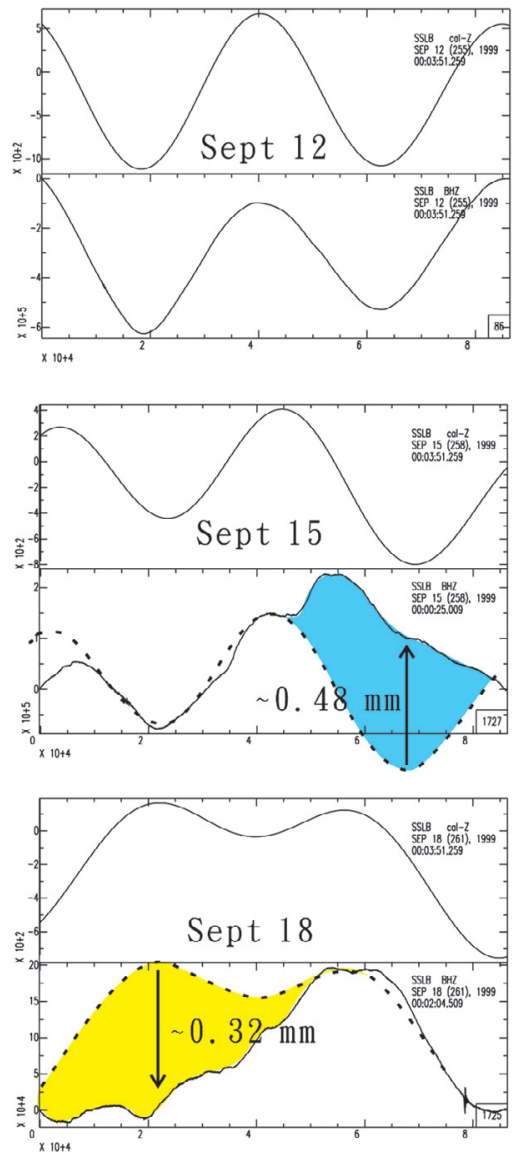
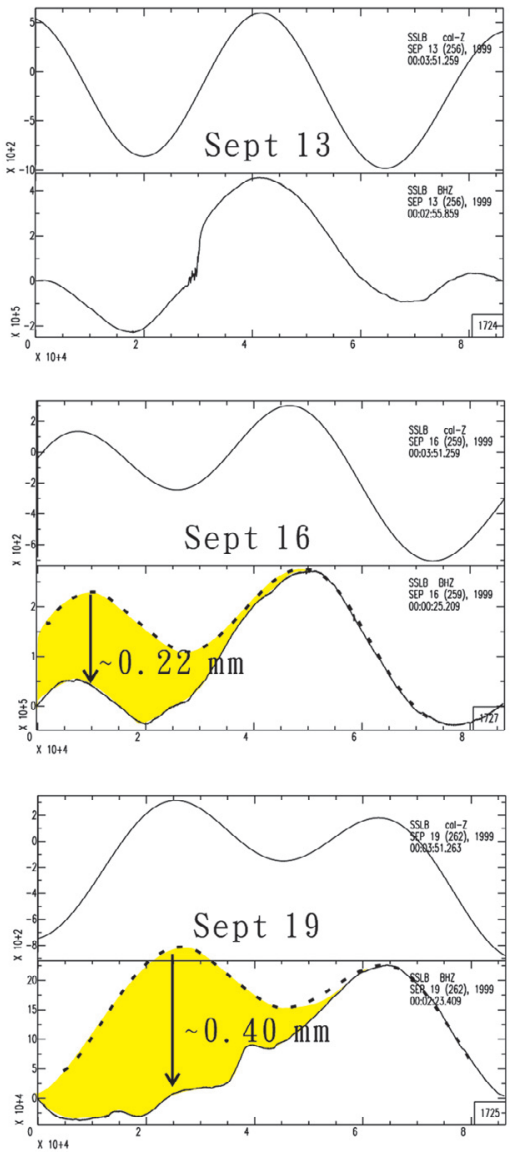
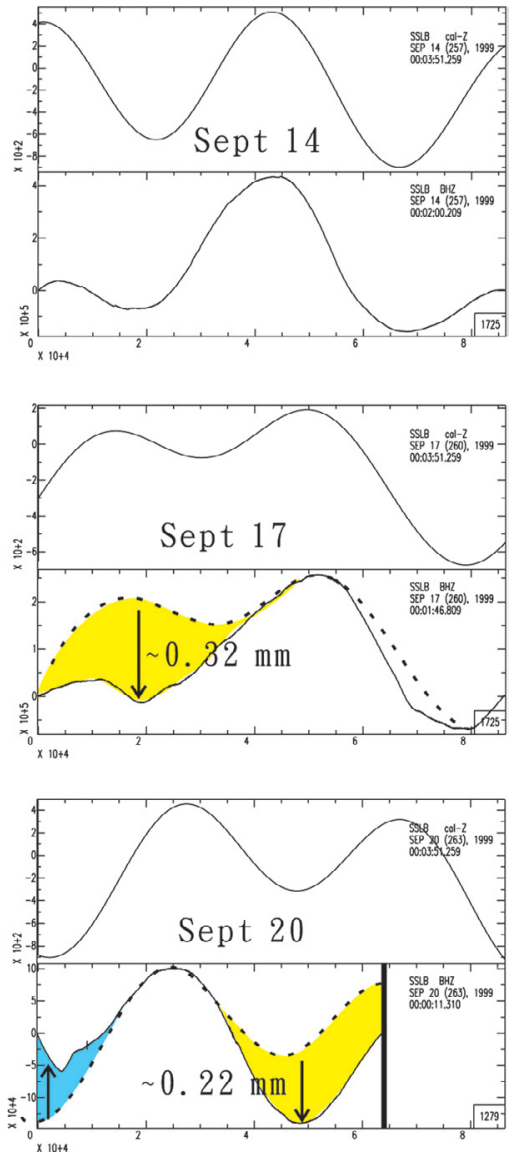

Fig. 4. (a) The calculated tidal forces (upper panels) and the comparison between calculated (dashed lines) and vertical displacements (solid lines) recorded at the SSLB station (lower panels) over 9 days (12 - 20 September) before the 1999 Taiwan Chi-Chi earthquake (marked by a thick line). The coloured regions here and the following figures show the major differences between the calculated and the observed tidal deformation. The maximum tidal anomaly either subsiding (yellow) or rising (blue) on each day is marked by arrows with values. (b) The calculated tidal forces (upper panels) and the comparison between calculated (dashed lines) and vertical displacements (solid lines) recorded at the NACB station (lower panels) over 9 days (12 - 20 September) before the 1999 Taiwan Chi-Chi earthquake (marked by a thick line). (c) The calculated tidal forces (upper panels) and the comparison between calculated (dashed lines) and vertical displacements (solid lines) recorded at the TWKB station (lower panels) over 9 days (12 - 20 September) before the 1999 Taiwan Chi-Chi earthquake (marked by a thick line). 
(b)
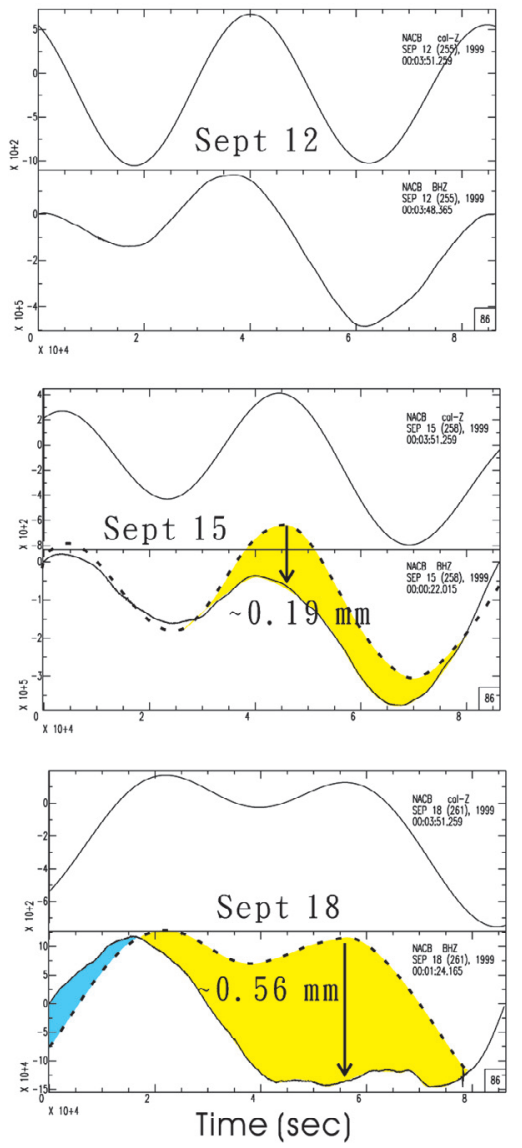

(c)
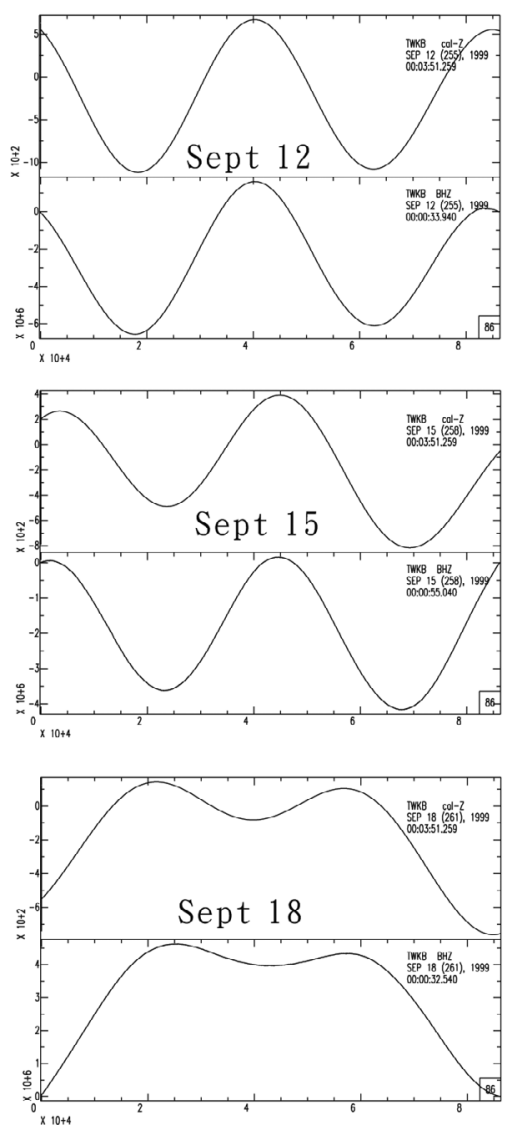
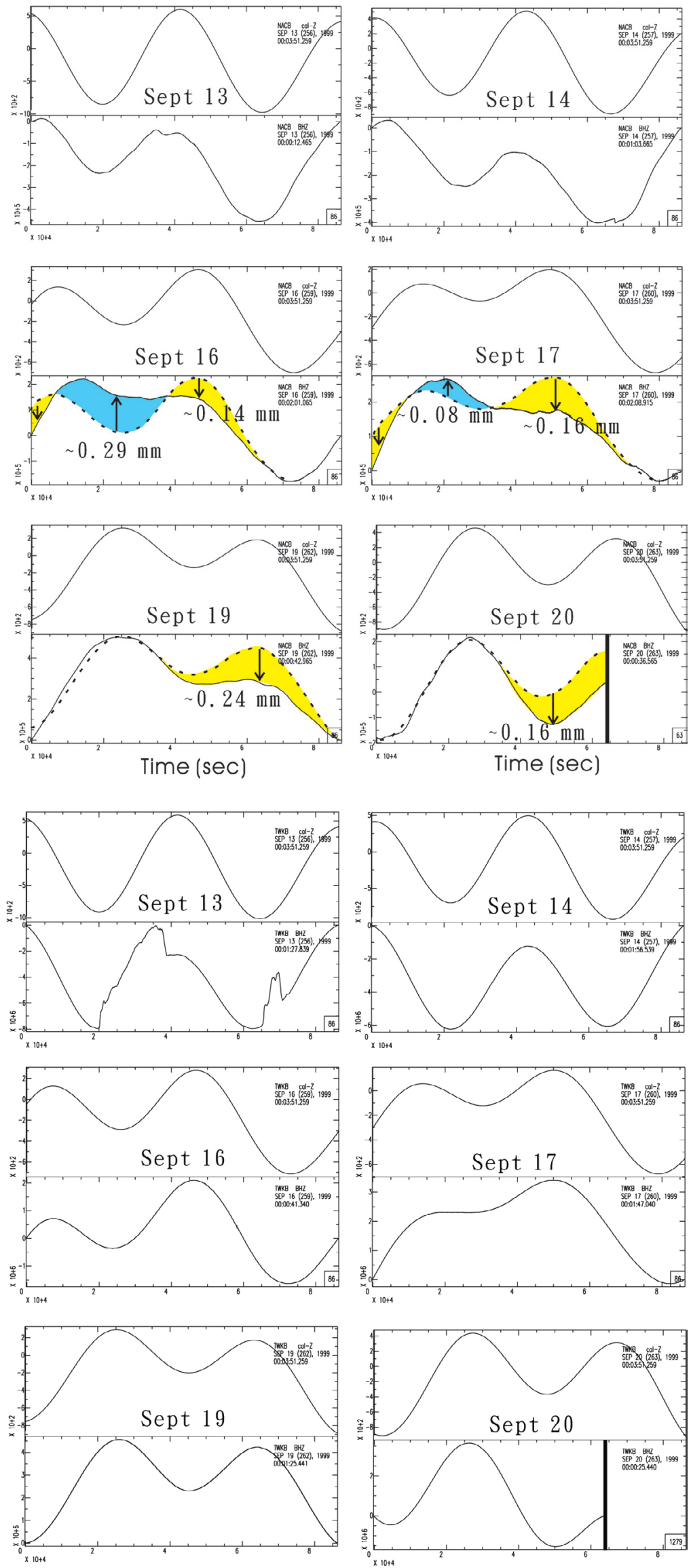

Fig. 4. (Continued) 
$0.48 \mathrm{~mm}$ at Station SSLB and slight subsidence of $0.19 \mathrm{~mm}$ at Station NACB on 15 September. Crustal deformation at the surface in central Taiwan generated by a slow slip earthquake along a nearly horizontal fault has been calculated (Fig. 5). A slip of $16 \mathrm{~cm}$ along a rupture area of $10 \mathrm{~km} \times$ $10 \mathrm{~km}$ at a depth of $12 \mathrm{~km}$ (Table 1) could generate the crustal deformations simultaneously observed at both stations. Similarly, the anomalous crustal deformations observed on 16 and 17 September can be explained by different simple faults along the same plane (Figs. 6 and 7).
On 18 and 19 September, the several-hour delay in anomalous crustal deformations observed between Stations SSLB and NACB might be explained by two separate slow slip events taking place along the fault plane at different times. On 18 September (Fig. 8), the first slow slip event (A) could have occurred NW of Station SSLB generating a significant subsidence (0.32 mm) at Station SSLB (Fig. 4a), but no crustal deformation at Station NACB in the early hours (Fig. 4b). The second slow slip event (B) could have occurred between Stations SSLB and NACB producing

(a)

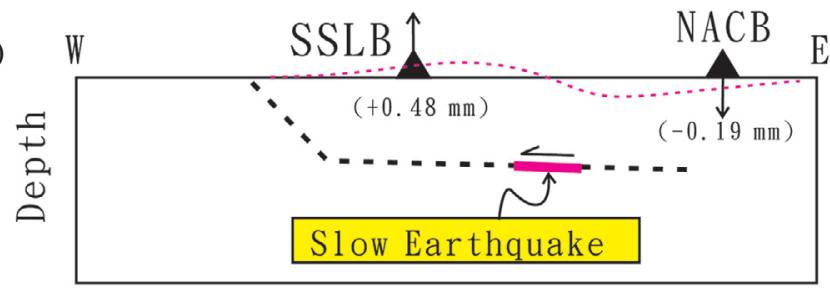

(b)

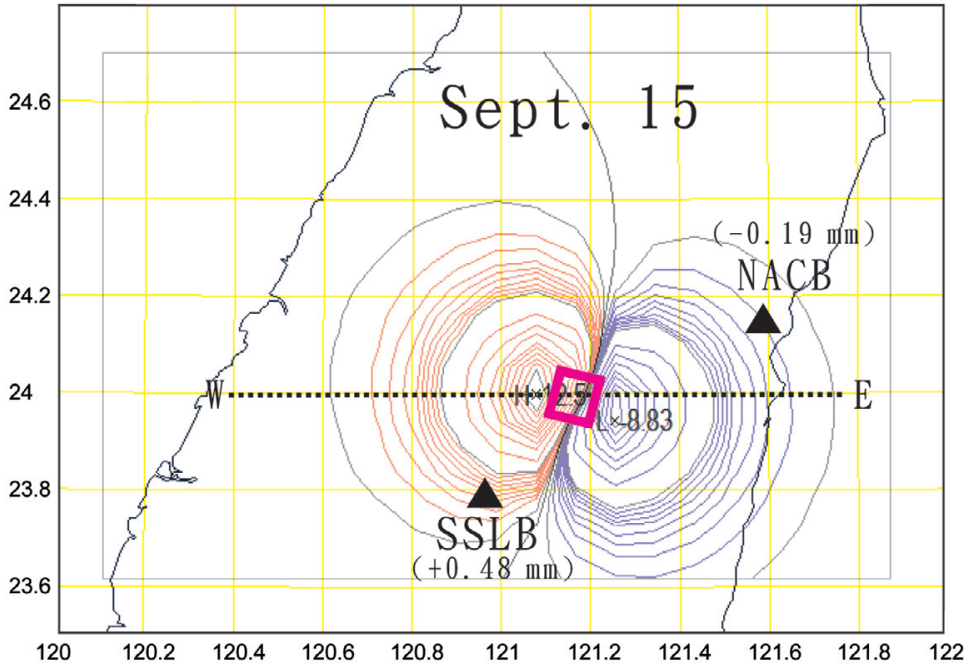

Fig. 5. Comparison between the calculated and observed crustal deformation at Stations SSLB and NACB (triangles) on 15 September. (a) Schematic projection of crustal deformation on the surface (thin dashed-line), and slow slip event (thick line) on the fault plane (dashed-line) along the W-E profile. (b) The surface crustal deformation (contours in log-scale intervals) generated by the slow slip event (thick block).

Table 1. Parameters for the slow slip events beneath central Taiwan.

\begin{tabular}{|c|c|c|c|c|c|c|c|c|}
\hline Event & $\begin{array}{c}\text { Depth } \\
(\mathbf{k m})\end{array}$ & $\begin{array}{l}\text { Slip } \\
\text { (m) }\end{array}$ & $\begin{array}{l}\text { Dip } \\
\text { (deg.) }\end{array}$ & $\begin{array}{c}\text { Rak } \\
\text { (deg.) }\end{array}$ & $\begin{array}{l}\text { Fault Plane } \\
\qquad\left(\mathbf{k m}^{2}\right)\end{array}$ & $\begin{array}{c}\text { Time } \\
(\mathbf{M} / \text { day })\end{array}$ & $\begin{array}{l}\text { Disp. at SSLB } \\
\quad(\mathrm{mm})\end{array}$ & $\begin{array}{c}\text { Disp. at NACB } \\
(\mathrm{mm})\end{array}$ \\
\hline 15 & 12 & 16 & 5 & 90 & $10 \times 10$ & $9 / 15$ & +0.48 & -0.19 \\
\hline 16 & 12 & 16 & 5 & 0 & $10 \times 10$ & $9 / 16$ & -0.22 & +0.29 \\
\hline 17 & 12 & 16 & 5 & 0 & $10 \times 10$ & $9 / 17$ & -0.32 & +0.08 \\
\hline $18 \mathrm{~A}$ & 10 & 9 & 5 & 90 & $10 \times 10$ & $9 / 18$ & -0.32 & $\sim$ \\
\hline $18 \mathrm{~B}$ & 12 & 6 & 5 & 90 & $10 \times 10$ & $9 / 18$ & $\sim$ & -0.56 \\
\hline $19 \mathrm{~A}$ & 10 & 20 & 5 & 90 & $10 \times 10$ & $9 / 19$ & -0.40 & $\sim$ \\
\hline $19 \mathrm{~B}$ & 12 & 5 & 5 & 90 & $10 \times 10$ & $9 / 19$ & $\sim$ & -0.24 \\
\hline
\end{tabular}


(a)

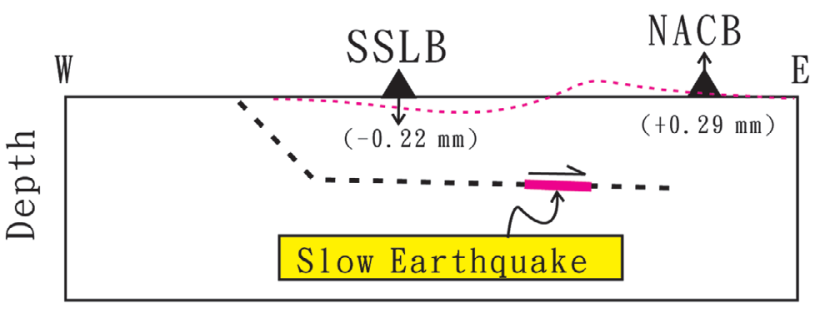

(b)

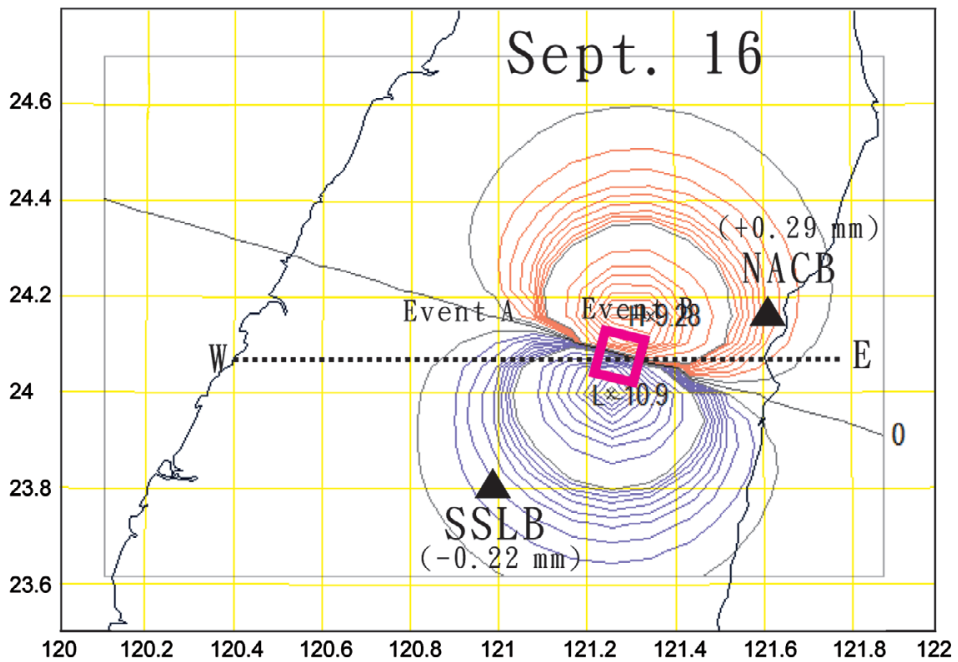

Fig. 6. Comparison between the calculated and observed crustal deformation at Stations SSLB and NACB (triangles) on 16 September. (a) Schematic projection of crustal deformation on the surface (thin dashed-line), and slow slip event (thick line) on the fault plane (dashed-line) along the W-E profile. (b) The surface crustal deformation (contours in log-scale intervals) generated by the slow slip event (thick block).

(a)

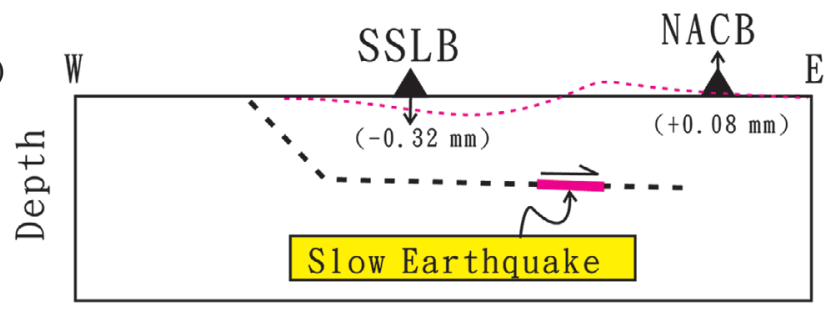

(b)

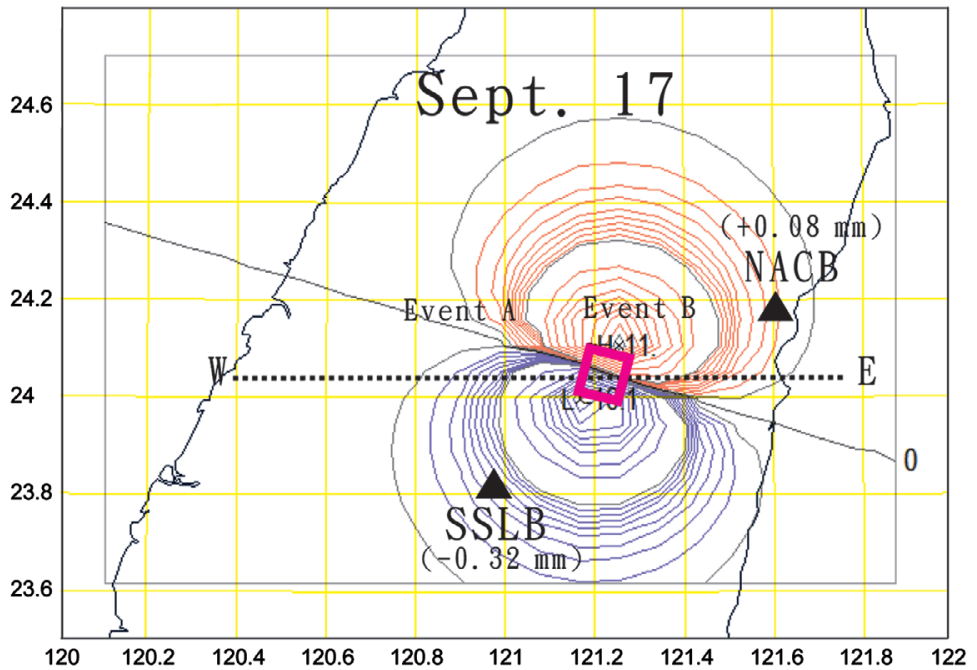

Fig. 7. Comparison between the calculated and observed crustal deformation at Stations SSLB and NACB (triangles) on 17 September. (a) Schematic projection of crustal deformation on the surface (thin dashed-line), and slow slip event (thick line) on the fault plane (dashed-line) along the W-E profile. (b) The surface crustal deformation (contours in log-scale intervals) generated by the slow slip event (thick block). 
(a)

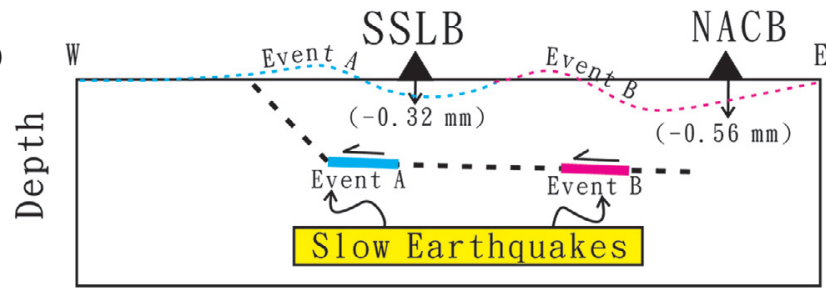

(b)

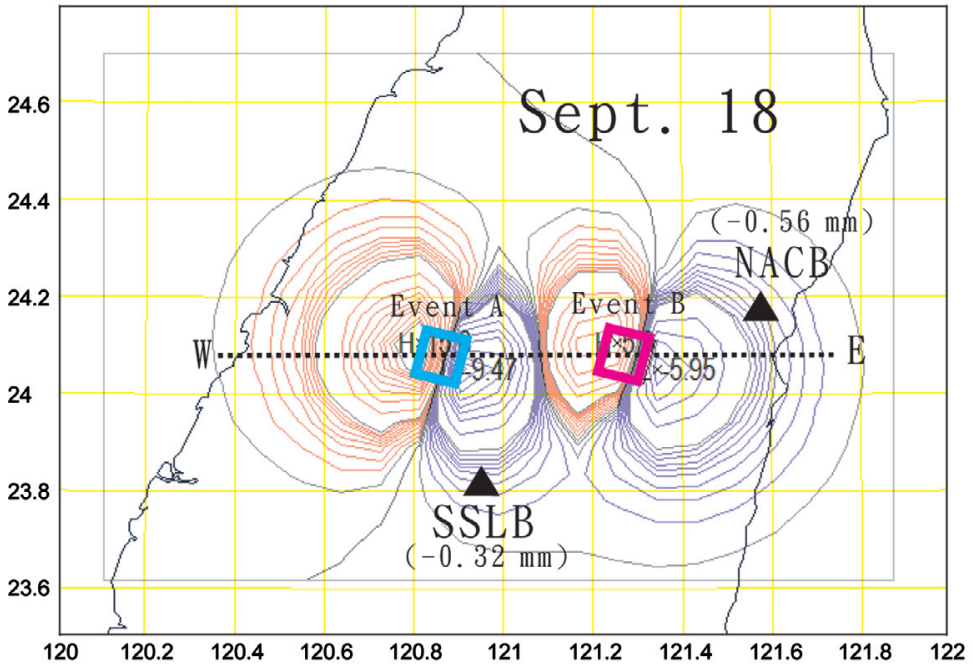

Fig. 8. Comparison between the calculated and observed crustal deformation at Stations SSLB and NACB (triangles) on 18 September. (a) Schematic projection of crustal deformation on the surface (thin dashed-line), and slow slip events (thick line) on the fault plane (dashed-line) along the W-E profile. (b) The surface crustal deformation (contours in log-scale intervals) generated by two slow slip events (thick block).

some subsidence $(0.56 \mathrm{~mm})$ at Station NACB, but no significant deformation at Station SSLB. In other words, the subsidence at both stations may have been generated by two different slow slip events jumping from west to east on the same day. The similar modelling of two slow slip events on 19 September is shown at Fig. 9.

\section{DISCUSSION}

Although the possibility of a sequence of slow slip events having taken place along an almost horizontal plane beneath the vicinity of the Chi-Chi earthquake is not well constrained by mathematical inversion, it is quite an acceptable possibility from a geological standpoint. Since the number of unknown parameters is significantly larger than that of observations, an exact solution cannot be obtained from the crustal deformation observed at only two broadband seismic stations. Like many other interesting problems in nature, this is an under-determined inversion problem with a non-unique solution. In other words, there are other possibilities for the generation of the same crustal deformations. However, as mentioned, the possibility of a slow slip occurring along the near horizontal plane of the decollement just prior to the Chi-Chi earthquake is an acceptable proposition (Fig. 10). Extremely high pore pressure along the possible decollement (Suppe 1981) could readily explain the mecha- nism for generating some of the slow slip events prior to the Chi-Chi earthquake. Occurrence of slow slip events in the decollement would help to induce the Chi-Chi earthquake along the Chelungpu fault wherein a significant volume of elastic energy had been stored.

Although the exact mechanism is not clear at present, observations of irregularities in Earth's tidal deformation from the broadband seismic data of central Taiwan are worth strong consideration as short-term precursors to the 1999 Taiwan Chi-Chi earthquake. The irregular tidal deformation repeatedly observed at some stations in the vicinity suggests that strained rock in the upper crust was very unstable. In addition to the regular gravitational forces of the sun and moon governing the tidal force, some anomalous force had been added to the crust disturbing the regularity of Earth's tidal deformation. In addition, the location and distribution of the irregular tidal deformation obtained from the broadband seismic stations might provide relevant information for determining the possible earthquake epicenter and magnitude. Closer stations to the epicenter have more of a chance of detecting irregular tidal deformation. Also, larger earthquakes might be detected over a broader area. Certainly, seismic station coverage would strongly influence the accuracy of any estimation of an earthquake's epicentre and magnitude.

The monitoring of possible earthquake precursors us- 
(a)

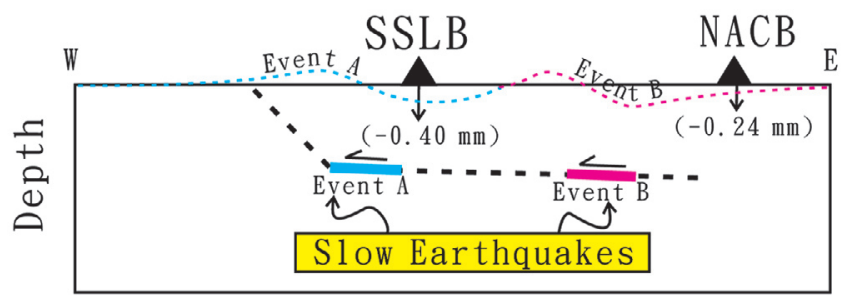

(b)

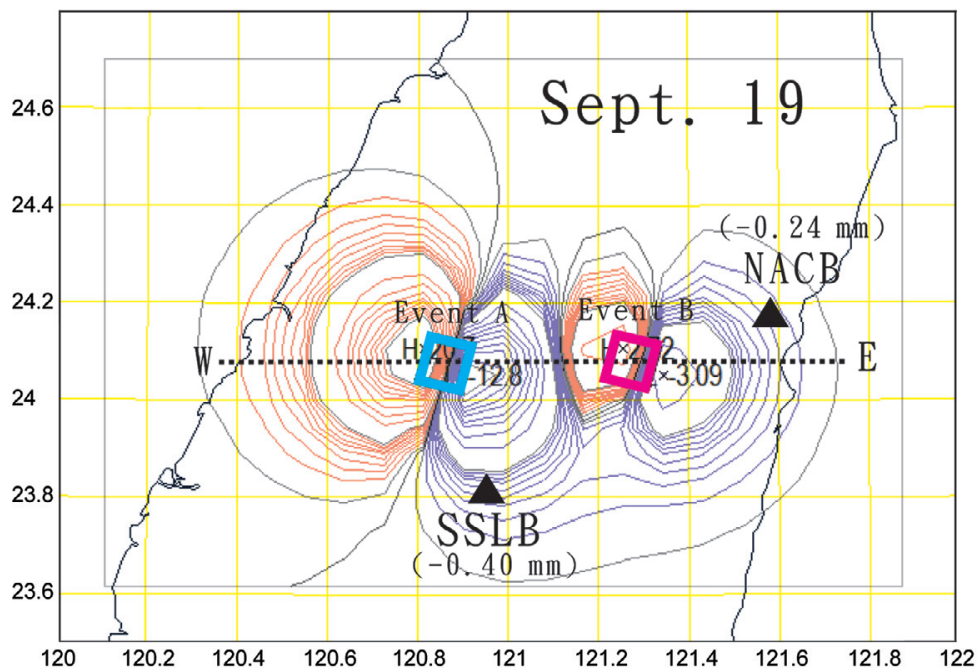

Fig. 9. Comparison between the calculated and observed crustal deformation at Stations SSLB and NACB (triangles) on 19 September. (a) Schematic projection of crustal deformation on the surface (thin dashed-line), and slow slip events (thick line) on the fault plane (dashed-line) along the W-E profile. (b) The surface crustal deformation (contours in log-scale intervals) generated by two slow slip events (thick block).

ing broadband seismic data has advantage over most of other observation methods or instruments. First, broadband data can provide the necessary sensitivity required for detecting small crustal deformations. Very small crustal deformations $(0.1-0.5 \mathrm{~mm})$ are difficult to observe by other measurements, such as GPS and water-level surveying techniques. Although strain-meters also provide high sensitivity to crustal deformation, they cannot be broadly deployed due to their extremely high cost and the time required becoming stable. Second, for the purposes of both immediate and continuous monitoring, broadband seismic stations are very useful because they are often equipped with realtime recording systems operating at high sampling rates (at least 100 points/sec). In other words, temporal monitoring of crustal deformation can be obtained in real-time from broadband seismic stations. Third, high-resolution crustal deformation can be directly integrated from velocity seismograms without complicated calculations and corrections. Forth, dense broadband-seismic-station networks in many seismic areas such as those of America's west coast, Japan, and Taiwan provide a better opportunity for detecting any precursors to large earthquakes at a short-distance. Fifth, the cost of installing a broadband seismic station is lower than that of other high-resolution instruments for observing crustal deformation. Finally, broadband seismic stations are multi-purpose. They can provide the possible capability

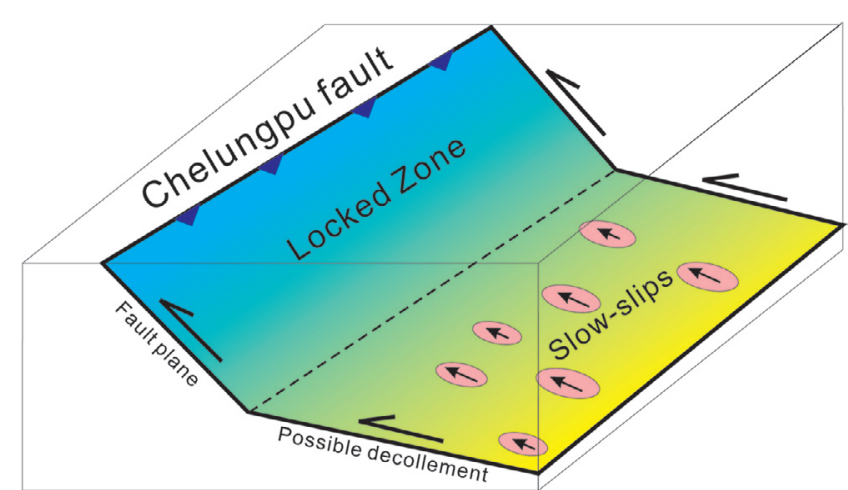

Fig. 10. Schematic of the source distribution for the Taiwan Chi-Chi earthquake along the Chelungpu fault and the slow slip events (an arrow within an ellipse) in the possible decollement. The mainshock occurred along the Chelungpu fault was likely preceded by a series of slow slip events on the decollement.

of detecting earthquake precursors and record high quality earthquake data for a wide variety of seismological studies.

\section{CONCLUSION}

Detailed examination of tidal crustal deformation from broadband seismic data in Taiwan shows that some anomalous crustal deformation occurred and was detected 
at two stations in central Taiwan several days before the 1999 Taiwan Chi-Chi earthquake. Delay in the detecting of anomalous crustal deformation between Stations SSLB and NACB indicates that the mechanism generating those anomalous crustal deformations is consistent in its temporary and spatial migration. Although slow slip events could possibly explain the irregular Earth tidal pulses preceding the earthquake, the exact mechanism cannot be obtained without further evidence. No matter what the exact mechanism was that explains the irregular patterns before the 1999 Taiwan earthquake, the anomalous crustal deformations observed at the broadband stations of SSLB and NACB could well represent earthquake precursors. Possible earthquake precursors of irregular Earth tidal pulses might be further confirmed by observing irregular Earth tidal pulses in other regions as well as Taiwan where dense broadband-seismicstation networks exist.

Acknowledgements The author would like to thank the Japan Seismological Society for providing the Micap-G software used to calculate the crustal deformation generated by the fault slip within the crust. Seismic data are provided by BATS DMC in Taiwan. Research funding provided by the National Science Council of Taiwan is appreciated.

\section{REFERENCES}

Castle, R. O., J. P. Church, M. R. Elliott, and N. L. Morrison, 1975: Vertical crustal movements preceding and accompanying the San Fernando earthquake of February 9, 1971: A summary. Tectonophysics, 29, 127-140, doi: 10.1016/0040-1951(75)90138-9. [Link]

Chang, H. C., 2000: Geological surveys for the 921 earthquake. Ministry of Economic Affairs, Taipei, Taiwan, $314 \mathrm{pp}$.

Chen, W. S., B. S. Huang, Y. G. Chen, Y. H. Lee, C. N. Yang, C. H. Lo, H. C. Chang, Q. C. Sung, N. W. Huang, C. C. Lin, S. H. Sung, and K. J. Lee, 2001: 1999 Chi-Chi earthquake: A case study on the role of thrustramp structures for generating earthquakes. Bull. Seismol. Soc. Am., 91, 986-994, doi: 10.1785/0120000731. [Link]

Cochran, E. S., J. E. Vidale, and S. Tanaka, 2004 : Earth tides can trigger shallow thrust fault earthquakes. Science, 306, 1164-1166, doi: 10.1126/science.1103961. [Link]

Dragert, H., K. Wang, and T. S. James, 2001: A silent slip event on the deeper Cascadia subduction interface. Science, 292, 1525-1528, doi: 10.1126/science.1060152. [Link]

Heki, K., S. Miyazaki, and H.Tsuji, 1997: Silent fault slip following an interplate thrust earthquake at the Japan Trench. Nature, 386, 595-598, doi: 10.1038/386595a0. [Link]
Hirose, H., K. Hirahara, F. Kimata, N. Fujii, and S. Miyazaki, 1999: A slow thrust slip event following the two 1996 Hyuganada earthquakes beneath the Bungo Channel, southwest Japan. Geophys. Res. Lett., 26, 3237-3240, doi: 10.1029/1999GL010999. [Link]

Houlié, N. and J.-P. Montagner, 2007: Hidden dykes detected on ultra long period seismic signals at Piton de la Fournaise volcano? Earth Planet. Sci. Lett., 261, 1-8, doi: 10.1016/j.epsl.2007.04.018. [Link]

Hsu, M. T., 1971: Seismicity of Taiwan and some related problems. Bull. Int. Inst. Seismol. Earthq. Eng., 8, 41160.

Hsu, Y. J., M. Simons, S. B. Yu, L. C. Kuo, and H. Y. Chen, 2003: A two-dimensional dislocation model for interseismic deformation of the Taiwan mountain belt. Earth Planet. Sci. Lett., 211, 287-294, doi: 10.1016/ S0012-821X(03)00203-6. [Link]

Lin, C. H., 2007: Tomographic image of crustal structures across the Chelungpu fault: Is the seismogenic layer structure- or depth-dependent? Tectonophysics, 443, 271-279, doi: 10.1016/j.tecto.2007.01.022. [Link]

Lin, C. H. and M. Ando, 2004: Seismological evidence of simultaneous mountain-building and crust-thickening from the 1999 Taiwan Chi-Chi earthquake ( $\mathrm{Mw}=7.6)$. Earth Planets Space, 56, 163-167.

Linde, A. T., K. Suyehiro, S. Miura, I. S. Sacks, and A. Takagi, 1988: Episodic aseismic earthquake precursors. Nature, 334, 513-515, doi: 10.1038/334513a0. [Link]

Linde, A. T., M. T. Gladwin, M. J. S. Johnston, R. L. Gwyther, and R.G. Bilham, 1996: A slow earthquake sequence on the San Andreas fault. Nature, 383, 65-68, doi: 10.1038/383065a0. [Link]

Liu, C. C., A. T. Linde, and I. S. Sacks, 2009: Slow earthquakes triggered by typhoons. Nature, 459, 833-836, doi: 10.1038/nature08042. [Link]

Okada, Y., 1985: Surface deformation due to shear and tensile faults in a half-space. Bull. Seismol. Soc. Am., 75, 1135-1154

Okada, Y., 1992: Internal deformation due to shear and tensile faults in a half-space. Bull. Seismol. Soc. Am., 82, 1018-1040

Reid, H. F., 1910: The Mechanics of the Earthquake, The California Earthquake of April 18, 1906. Report of the State Investigation Commission, 2, Carnegie Institution of Washington, Washington, DC.

Roeloffs, E. A., 2006: Evidence for aseismic deformation rate changes prior to earthquakes. Annu. Rev. Earth Planet. Sci., 34, 591-627, doi: 10.1146/annurev.earth. 34.031405.124947. [Link]

Sagiya, T., 1998: Crustal movements as earthquake precursors - Leveling anomaly before the 1944 Tonankai earthquake revisited. Bull. Geogr. Surv. Inst., 44, 23-36.

Sato, H., 1977: Precursory land tilt prior to the Tonankai earthquake of 1944: In some precursors prior to recent 
great earthquakes along the Nankai trough. J. Phys. Earth, 25, S115-S121.

Sato, H., 1982: On the changes in the sea level at Tosashimizu before the Nankaido earthquake of 1946. J. Seismol. Soc. Jpn., 35, 623-626.

Shin, T. C., K. W. Kou, W. H. K. Lee, T. L. Teng, and Y. B. Tsai, 2000: A preliminary report on the 1999 Chi-Chi (Taiwan) earthquake. Seismol. Res. Lett., 71, 24-30, doi: $10.1785 / \mathrm{gssrl} .71 .1 .24$. [Link]

Suppe, J., 1981: Mechanics of mountain-building and metamorphism in Taiwan. Mem. Geol. Soc. China, 4, 6789.
Yu, S. B., L. C. Kuo, Y. J. Hsu, H. H. Su, C. C. Liu, C. S. Hou, J. F. Lee, T. C. Lai, C. C. Liu, C. L. Liu, T. F. Tseng, C. S. Tsai, and T. C. Shin, 2001: Preseismic deformation and coseismic displacements associated with the 1999 Chi-Chi, Taiwan, earthquake. Bull. Seismol.Soc.Am.,91,995-1012, doi: 10.1785/0120000722. [Link]

Yu, S. B., Y. J. Hsu, L. C. Kuo, H. Y. Chen, and C. C. Liu, 2003: GPS measurement of postseismic deformation following the 1999 Chi-Chi, Taiwan, earthquake. J. Geophys.Res., 108,2520, doi: 10.1029/2003JB002396. [Link] 